Article

\title{
Practicing Patienthood Online: Social Media, Chronic Illness, and Lay Expertise
}

\section{Collette Sosnowy}

The Graduate Center of the City University of New York, 365 Fifth Avenue, New York, NY 10016, USA; E-Mail: csosnowy@gc.cuny.edu; Tel.: +1-484-949-4408

Received: 31 March 2014; in revised form: 2 June 2014 / Accepted: 9 June 2014 /

Published: 13 June 2014

\begin{abstract}
The use of digital technologies and social media by people with serious illness to find, share, and create health information is much celebrated but rarely critiqued. Proponents laud "Health 2.0" as transforming health care practice and empowering patients. Critics, however, argue that a discourse of developing lay expertise online masks the disciplinary practices of the neoliberal state's emphasis on individual responsibility. Notably, the perspectives of people who are engaging with social media related to their health and illness are under-represented in this debate. This research examines the experiences and perspectives of women who blog about their lives with Multiple Sclerosis in order to situate them in the context of these conflicting ideologies. Methods consisted of an ethnographic content analysis $(N=40)$, an online survey $(n=20)$, and an online discussion forum $(n=9)$. Findings revealed that blogging is neither inherently empowering nor inevitably disciplinary. Rather, it simultaneously offers opportunities for patients to gain medical knowledge and resist medical patriarchy, as well as compounds expectations placed upon patients to assume greater responsibility for managing their care.
\end{abstract}

Keywords: social media; blogging; Multiple Sclerosis; Health 2.0; qualitative research

\section{Introduction}

Social media platforms facilitate the sharing of health information between users and the co-creation of new knowledge that is shaped by personal experience. As such, they are a unique location to read narratives of women's experiences with illness because they provide insight into lived experience as told through a public forum. Social media can provide important spaces for people with illness to build community, engage in activism, and enact resistance. Numerous studies document 
the perceived benefits of using social media and being part of online illness communities [1-11], opportunities for people to find information and develop medical knowledge [12-17], and challenge medical expertise [18]. Ziebland and Wyke [19] identified multiple domains through which online activity can affect health, several of which fulfill social needs, such as connecting to others and narrating experience. They argue that the appeal of hearing about others' first hand experiences as well as the ability to contribute to and construct medical knowledge are important components of seeking health information online. Certainly, social media applications are a key facilitator for these activities.

Skepticism of the internet as a reliable source of health information and resistance from some health care providers have lessened considerably since early widespread adoption of the medium [19]. Applications like blogging are now helping to facilitate a shift in patients' roles [15,17,20-26] in which they are increasingly both enabled and expected to develop lay expertise about their illness and treatment, including seeking and sharing health information online through interactive networks. Equally, practitioners are supposed to encourage these activities and welcome patients as partners in care [27]. People with illness who use social media are often portrayed as technologically-empowered citizens who actively strive to participate in their care, collaborate with providers, educate themselves and others about their illness, and self-manage their care.

While laypeople have initiated many of these social media practices, the health care industry has further promoted them as part of a model of participatory patient-hood that has the potential to "revolutionize" health care by accelerating knowledge development and contributing to advances in research, ultimately improving treatments and outcomes. Many companies, organizations, and agencies in the public and private sectors of the health care industry have rushed to position themselves in the social media landscape in order to market, shape, and influence their sectors of the economy as well as influence policy. They use the internet to promote a discourse that participation in social media is inherently empowering and that patient engagement via this media will dramatically shift health care for the collective benefit. Examples can be found on the websites of health insurance companies, advocacy organizations, and other industry stakeholders that feature patients who blog or appear in video presentations talking about their personal experiences with illness and treatment. While these profiles highlight the significant experiential knowledge patients have acquired and developed on their own, they also imply that taking on this role is inherently empowering rather than a product of necessary labor.

Critics, on the other hand, argue that this vision of participatory patient-hood, which incorporates a discourse of individual responsibility that is characteristic of neoliberalism, masks disciplinary practices of the state. As Foucault [28] conceived, discipline of the citizen is achieved in part through the indirect means of guiding individuals to discipline themselves. Drawing from Foucault's technologies of the self. Rose [29] argues that under neoliberalism, a political, social, and cultural ideal of an "enterprising self" who strives toward an idealized conception of the citizen reproduces the reductive effects of neoliberalism. More specifically, this conception has come to include using internet applications to acquire and share information in order to direct, manage, and improve one's health. In framing these practices as acts of choice, the shifting of responsibility from the collective to the individual is simultaneously celebrated and downplayed.

While neoliberalism is fundamentally opposed to collectivism, the potentials of social media to collect massive amounts of data and influence large numbers of people provide another venue through 
which to discipline and profit from citizens. Individuals are encouraged to donate personal health information and labor in the name of furthering medical innovation, thus benefitting the greater population. Meanwhile, both the health care industry and the state profit directly and indirectly from their efforts. A discourse of health activism reorganizes collectivism and turns it around so that it is no longer an oppositional practice, but a cooperation between public, proprietary, and personal interests. The promotion of using social media to conduct and maintain self-disciplinary practices can also be seen as reproducing structural inequalities by deflecting attention away from the inadequacies of the state and industry to care equally for its citizens and by excluding people who cannot or choose not to practice participatory patient-hood.

Lost between the divergent viewpoints of industry advocates and academic critics, however, are the voices of people who are engaging with social media related to their health and illness. They blur the boundaries between these ideological distinctions through their lived experience with illness. In practice, patients must negotiate between these perceived opportunities and obligations to meet their needs. This research focuses on the social media of blogs as narratives about life with chronic illness, in order to understand how blogging is a forum through which these negotiations are related and practiced.

\section{Situating Social Media in Health Discourse}

Miller and Pole credit the user-generated content characteristic of a more interactive online environment with being responsible for the rapid growth in health-related content online and call blogging the "quintessential Web 2.0 application" [12] (p. 1514). Digital technologies and social media have become so integrated in shaping a new cultural paradigm of health care that some in the industry have coined the term "Health 2.0", which Sarasohn-Kahn defines as "the use of social software and its ability to promote collaboration between patients, their caregivers, medical professionals, and other stakeholders in health" [22] (p. 2). Eytan best describes the concept's ideological goals and discourse:

Health 2.0 is participatory healthcare. Enabled by information, software, and community that we collect or create, we the patients can be effective partners in our own healthcare, and we the people can participate in reshaping the health care system [30].

Such impassioned and enthusiastic discourse found in the quote above is common among advocates of this approach, illustrated here by such terms as "partners", "reshaping", and even "we the people".

The ideologies behind Health 2.0 need further examination. Writing about personal data-reporting online, Levina [31] argues that donating information via online social networks creates the perception that "active patient citizens" align themselves with acts of rebellion against the traditional medical patriarchy that seeks to maintain control of health information and expertise. However, this idea can obfuscate problematic aspects, particularly the ethical implications of who else benefits from this freely-given data, that is, the companies that sell it. Rose and Novas argue that the state constructs patients as "biological citizens" whose bodies are the sites of neoliberal "citizenship projects". They argue that "activism and responsibility have now become not only desirable but virtually obligatory" [32] (p. 451) to fulfilling the patient's idealized role as equal participant. These 
expectations are partially the product of public and private institutions that seek to discipline citizens by constructing personal responsibility as a moral imperative, and an act of empowerment and autonomy. Salmon and Hall note that the discourse of empowerment "clearly connects with the wider political and cultural emphasis on individual autonomy and rights that is helping the state shed the responsibility for individuals that citizens had come to expect” [27] (p. 55).

\section{Critiquing the Information-as-Empowerment Narrative}

Assumptions that access to information allows patients opportunities for empowerment and better care are embedded in the construction of participatory patient-hood. However, as Wathen and Harris describe, critics question the clinical value of the information-as-empowerment model and whether these policies and practices are of greater benefit to the patient or the health care system:

"Accompanying the current discourse on health care reform, in which terms such as patient empowerment and self-care often appear, is the assumption that health-informed individuals will participate, alongside their health care providers, in a process of shared decision making. Ultimately, the logic follows, informed empowered patients will take responsibility for their health, including managing their health care" [14] (p. 640, emphasis in the original).

The authors note that these assumptions may be inconsistent with patients' desires to shoulder these responsibilities. Furthermore, their research suggests that access to information alone is unlikely to fill in for important care relationships. In interviews with rural Canadian women about their health information-seeking experiences, they found that participants repeatedly focused on the quality of their relationship to the people they turned to for help and information. They concluded that "the perceived effectiveness of these health information intermediaries seemed to depend largely on how well they expressed care and concern during the information exchange" [15]. Similarly, Salmon and Hall argue that "patients value being given information as a way of building relationships with clinicians and maintaining hope — not as a basis for decision-making" [27] (p. 53).

Several scholars $[6,27,33]$ have argued that the transitions in both discourse and practice are the product of consumer society and its impact on health care. Kopelson [33] maps the transition of the internet-informed patient from nuisance to expert, partner, and manager of their illness and notes that the latest iteration is becoming a prescriptive norm that crowds out other ideologies and behaviors. This is accomplished by creating and recruiting the ideal patient, and portraying those who do not conform as failed consumers who elect not to engage in the enterprising practices of information-seeking and body discipline. The result is a "felt imperative" [34] to enact these behaviors and adopt its goals. Salmon and Hall argue that the idea of empowerment through information is not generated by patients but by those it benefits - providers and, by extension, the health care industry. By not interrogating assumptions about empowerment, providers may be unaware that they are "redrawing the boundaries of medicine" [27] (p. 55) in a way that is burdensome to the patient.

Distinctions between proponents and critics of the participatory e-patient discourse are made more ambiguous by the intersections between the individual patient's interests and the interests of other stakeholders. For example, pharmaceutical companies benefit from developing and selling the 
hugely expensive drugs required to treat MS, yet patients need and benefit from them. Advocacy organizations such as the National MS Society, which are often focused on raising money for further research, have closely aligned interests with, and often receive funding from pharmaceutical companies, but rarely disclose these relationships [35]. However, their efforts may help develop better treatments. Substantial resources are poured into consumer education efforts, both by the state through public health campaigns, and by the insurance, pharmaceutical, and hospital industry as cost-effective strategies, yet they provide the individual with important information. These industries have embraced the use of social media, in part, to promote a model of patient-hood that increases their profitability, yet individuals may feel empowered by using social media to engage in their health care.

The argument that the demands placed on the patients in the current political economy are necessarily burdensome is flawed when applied to the more nuanced experience of being a patient. As I demonstrate in my argument, some patients genuinely feel empowered by their increased ability to be more knowledgeable and more participatory in their care, even as they recognize the burdens and constraints placed on them. While there may be little they can do to influence change in an abstract and unwieldy health care system, they can acquire more skills that help them to negotiate it to their best advantage. This paper argues for a most nuanced understanding of using social media to develop and share knowledge and personal experiences. The political implications of greater patient participation - which both challenges and contributes to medical knowledge and practice - remain significant but are increasingly less novel. Looking at the everyday experience of patients that have chosen to enact this role, as this study does, reveals the ways in which the larger cultural discourse of this model of patient-hood are lived.

\section{Methods}

This mixed-methods study focused on American women with Multiple Sclerosis who regularly maintained journal-style personal blogs about their lives. Data consisted of three phases: an ethnographic content analysis of 40 blogs $(N=40)$, an online survey of the bloggers $(n=20)$, and an online discussion forum with bloggers $(n=9)$ for a period of 5 weeks, all explained in greater detail below. Chronic illness such as MS requires daily negotiations with often-unpredictable symptoms over the lifespan. I chose to focus on chronic illness because I wanted to broaden the literature about online illness narratives and health discourse. There is a substantial body of work on cancer-related (especially breast cancer) blogs, online communities, and online advocacy and activism that lays a groundwork for the study of online illness narrative $[2-7,11,36]$, but less research has examined different types of illness.

The nature of the internet as a continually-changing forum opens up new perspectives and arguments for methodological and ethical approaches. Because it is a relatively new field of academic study, fewer standard practices have been established for protecting human participants than for traditional fieldwork. A great deal of internet research includes collecting and analyzing content or observing user behavior without individuals knowing they are being included in research. Hutchinson [37] outlined three schools of thought about using personal online content for research without permission, even when it is publicly-accessible: (1) publicly available information is public and therefore should be able to be researched without explicit permission [38,39]; (2) personal 
information, such as blog entries and comments, while public, are personal and should be treated as private [40-42]; and (3) the Internet is "publicly-private and privately-public" [43] (p. 131) and should be treated with a balanced approach. The blurring between public and private that is characteristic of social media make a strong case for the latter.

This study was deemed by the IRB to be low-risk and I chose to take a balanced approach by making two of the three phrases participatory. This was not simply to address ethical concerns, but also because participatory research was a primary goal of this project. I sought to elicit bloggers' voices directly, put them in conversation with each other, and ask them to consider specific topics and questions. I determined that the blogs I included in this study, while personal, were intended to be read by a wide audience. In addition to documenting their personal experience, bloggers often wrote about Multiple Sclerosis advocacy efforts, and shared information and advice. There were also some visible interactions between bloggers and commenters, indicating a willing engagement with a public audience. To protect participants' identities, survey responses were anonymous, and the discussion took place on an invitation-only, password-protected platform. Furthermore, I asked discussion participants to choose their own usernames and emphasized that I would use these when I referred to or quoted them individually, as I do here.

Three phases were conducted over a period of three months.

Phase 1. An ethnographic content analysis of 40 blogs. In conducting an analysis of blog content, which included text, graphics, images, and video, I used Altheide's methodology of ethnographic content analysis. This approach involves:

Emergent and theoretical sampling of documents from information bases (including those developed by a researcher, e.g., field notes), development of a protocol for more systematic analysis, and then constant comparisons to clarify themes, frames, and discourse [44].

Following an overall reading of the blogs using this approach, I conducted a more detailed analysis of 78 posts (in most cases, two per blog). These were selected by choosing two dates and analyzing the most recent post.

Phase 2. An online survey. I sent an anonymous online survey to all 40 bloggers from Phase 1 and received 20 responses. With the survey I sought to understand participants' blogging practices and the role blogging played in their lives and experience with illness. I asked respondents to provide an email address if they were interested in further participation and invited all who did to take part in an online discussion forum.

Phase 3. An online discussion forum. Nine bloggers participated in a private online discussion forum for a period of five weeks. This method directly solicited the perspective of the bloggers and provided them an opportunity to connect with other bloggers who write about having MS. Three overlapping themes were explored over the course of the discussion: (1) being a part of the MS "blogosphere" and feelings of connection to other bloggers or other people with MS; (2) expectations of patients by the medical establishment to be participatory patients; and (3) the blend between their online and offline experiences.

I used a grounded theory approach [45] for analysis. This approach allows hypotheses, categories and conceptual codes, and themes to emerge from the data collection and analysis. In this approach, sampling is aimed toward theory construction, not representativeness. I analyzed data using a method 
of "open-coding" followed by "focused-coding" [46]. I categorized data based on the major themes that had arisen from initial reading of the text and descriptive statistics, such as medical knowledge or interactions with healthcare providers, and motivations for blogging. I then identified recurrent patterns and sub-themes, such as a specific focus on neurologists, or a love of writing.

For the purposes of this article, I limit the analysis of findings to Phase 3 and focus on how bloggers developed and shared medical knowledge and utilized it in their care.

\section{Developing Lay Health Knowledge}

Inevitably, patients are constrained by their need for health care and a relative lack of influence over an unwieldy medical bureaucracy. Facing such odds, they are left with little choice but to navigate their way through the system, advocating for themselves and their families as best as they can. Findings from this study revealed that while the disease itself was most often seen as an unwelcome burden, both the opportunity and necessity to become a participatory e-patient was not necessarily seen in the same light. Most of the discussion participants saw it as providing opportunities for them to feel more in control of their life with illness. Participant "funkymango" wrote, "I want to be a partner in my healthcare. It's my body, so if it's down to choosing between two meds (for instance) I want to be involved in the decision-making." These findings contradict Salmon and Hall's [27] suggestion that the construction of patient empowerment is not often experienced as such. These participants, at least, did desire to be informed and have the ability and option to influence their treatment. This is perhaps not surprising from a set of participants who were already actively seeking and sharing information online and may be more likely to take this view than people who do not engage in these behaviors. Nevertheless, this finding demonstrates that while interrogating the assumptions and vocabulary of medical discourse is important, as Salmon and Hall [27] did 10 years ago, we need to revisit these questions in the context of a newer media landscape where social interactions online are easy, ubiquitous, and integrated with lived experience. Furthermore, a discourse of empowerment has become even more embedded in our cultural conceptions of health care practice and patient-hood through social media.

While participants in this study saw these opportunities as benefits, they also didn't feel they had much of a choice if they wanted to be certain they were getting the best care and outcomes possible. Participant "turtlespeed" highlighted this contradiction when she stated, "I like being an informed patient but it does make for a lot more work. I guess I kinda feel that it is just part of being a patient. You need to be able to understand what is going on so you can advocate for your care." Bloggers developed medical knowledge through their own efforts at self-educating, but they also assumed the role of lay expert by choosing to share and discuss this information on their blog and interacting with others online. Many of the participants considered themselves educators and translators of complex medical information and blogs provided a wide-reaching forum for their work. As a result, they saw themselves as having a responsibility to readers to provide accurate and up-to-date information that was supported by scientific research. In addition to carefully crediting sources, bloggers were careful to make clear distinctions between research-based expert knowledge and their personal experiences.

In the discussion, participant "sheltiemom" described the benefits and risks associated with using the internet to get information when she wrote, "we do have to be careful because while the internet 
can be helpful there is alot of Crap info out there also. It seems everybody has some crazy cure for MS." In response, "funkymango" wrote "This is so true...I think this puts some responsibility on us as MS bloggers/bloggers about MS to make sure the information we give is accurate." Similarly, "sherri" warned:

There are bloggers out there who do their own "research" and draw their own conclusions, then go and post it as medical based knowledge. This is very dangerous. If a newly diagnosed or very naïve person reads the information as legitimate, they might face some problems....I think that being a personal blogger carries some responsibility but not near as much as someone who is blogging and calling it research...those research based bloggers should be held to a much higher level of responsibility and standard.

Personal accounts of a blogger's experience were seen as equally helpful, if not more so, than research-based information. For "sherri", other bloggers' personal experiences were the most helpful to her because they supplemented the information she received from her doctor or researched herself, and allowed her learn from others' experiences with the disease. She wrote that on some of the blogs she read:

...there was no declaration of fact - only personal stories. In my mind, these were the best sources of information for me. I could compare what I was reading on personal sites to research or things my [neurologist] had said, which helped me understand the disease.

For her, both kinds of information were seen as equally valid and complemented each other. Making a clear distinction between professional and lay expertise highlighted this symbiosis, rather than simply privileging professional expertise. Developing knowledge about the biological functions of MS provided a context in which to place the embodied experience of the disease, but the most intimate knowledge of the disease came from living with it. Bloggers' often described daily experiences - descriptions of symptoms, notable incidents like a fall, accommodating daily routines due to fatigue, or pushing oneself too hard - rather than, or in addition to, research-based information. This embodied knowledge was acquired over time, and linked with the medical knowledge they learned from formal sources.

Not surprisingly, health care providers, specifically neurologists, played a significant role in bloggers' lives, even when actual encounters were infrequent. This significance was not only important to the physical treatment of the disease, but to their emotional experience as well. Encounters and relationships with medical providers were most often described in polarized terms: either positive experiences or negative/contentious experiences, suggesting that these relationships are highly charged. These important relationships were negotiated between what bloggers expected of themselves as patients and what they expected of their neurologists. In addition to wanting to be knowledgeable enough to be part of decision-making about their care, they wanted doctors who considered and respected their knowledge. This is consistent with Wathen and Harris's [15], and Salmon and Hall's [27] findings about the importance of the quality of relationships in receiving health information.

Bloggers' ability to fill the role of self-advocate and partner in their care was not one-sided. It was also partly contingent on healthcare providers meeting the patients' expectations. The bloggers expected their doctors to respect them as people, treat them as knowledgeable patients, and to care about them. 
Likewise, their satisfaction with healthcare providers was largely dependent on how well providers fulfilled these expectations. When a provider did not, bloggers usually found a new one who did. While most bloggers assumed that their neurologists were well-qualified, those who did not meet expectations for a caring and respectful relationship were usually described as having a patronizing attitude and resistant to patient input. While bloggers wanted to be considered a partner in their care, they also sought to maintain the distinction between professional expertise and the lay expertise they developed from personal experience and wanted their health care providers to be more knowledgeable and able to guide them in decision-making.

Participant "ellie", a former physical therapist, said that she was "treated [respectfully] as a person with knowledge" by doctors most of the time. She enacted the role of participatory patient by maintaining a chart of her health, which she brought with her to doctors' visits. However, she wrote, "even though I am and want to be a knowledgeable partner I need him to be a caring MD". She described a recent appointment, in which her doctor was attentive and supportive, and wrote "he was my physician and I was his patient...and that's what I needed at that time". Likewise, "katewj" also described feeling the need to direct her own care: "my treatment is very much 'in silos' and I have to be the communicator who thinks to ask one specialist about the effects generated by another". She also wrote "I want to be an empowered, informed patient AND I hope for doctors who are more informed than I." Several bloggers described feelings of satisfaction from being included in decision-making, such as "sherri" who wrote, "he gives me his opinion, allows me to research things, and then together we make decisions about what is going to be next".

In contrast, participant "sheltiemom" described a neurologist who had a "go home sit on the couch and die' attitude". Fortunately, she was able to switch to a doctor who was more proactive and receptive to her participation. A few bloggers, however, had either not been able to switch to a new neurologist or had switched but still not found one they were happy with. "grace 2 wheel" described "an endless battle with doctors who have too much power over my access to medical care as well as the all important disability insurance. To be blunt, I dread seeing my neurologist." "marie" wrote that she been to three neurologists in her local area:

The neurologists have been mostly arrogant and close-minded, needing to be in control and, locally, out of date with treatment protocols. Very threatened by any suggestions of knowledge by me, the patient....It is very disheartening, as a patient with a chronic disease, to feel you are not understood or respected as an intelligent, informed adult.

While patients are enabled to be well-informed about their illness, the inherent power structures in health care still limit their role to contributing information to the provider's expertise. The extent to which their knowledge, experience, and desire can help direct their care, however, is partly contingent on their medical providers' sharing their ethos.

\section{Limitations of the Study}

Much internet-based research, particularly early studies, relied heavily on unobtrusive observation by researchers and while observation is a rich source of data, I believe that connective media calls for participatory methods. With this in mind, I solicited the perspectives of bloggers directly in order to 
better understand their experiences as they saw them and chose to write about. In addition, by using three distinct methods (an ethnographic content analysis, an online survey, and an online discussion), I approached the topic from multiple vantage points.

As with all methods, however, these three had some limitations. In studying public blogs, I chose subjects who openly share their personal viewpoint. This means that my findings are specific to the small minority of American women with MS who blog publicly, and don't represent the hundreds of thousands of women with MS who do not. However, drawing on the support of literature about online illness communities [1-11], I found similar themes about living with illness (such as describing the disruption caused by illness and strategies for working around limitations). It is reasonable to assume that some commonality is shared by bloggers and non-bloggers alike.

As public bloggers, these women may be more comfortable sharing their thoughts and stories and be predisposed to participate in a research project compared to private bloggers or non-bloggers. A certain amount of self-selection probably contributed to the willingness and enthusiasm of the nine bloggers who elected to participate in the online discussion. Nonetheless, this study adds important voices and the themes could be extrapolated to other contexts.

\section{Conclusions}

Being a participatory patient who uses digital tools to acquire, share, and develop knowledge is neither inherently empowering, nor does it shift an undue burden onto the patient. It offers opportunities to feel empowered by acquiring information and connecting with others. It is also undeniably a laborious practice that has become a more common expectation by both patients themselves and the health care industry to take full advantage of the large amount of information made available through easily-accessible networks. In this study, it is clear that the practice of utilizing digital and networked tools, is accompanied by other social practices such as fostering community and mutual support, and negotiating medical relationships.

Overall, the bloggers viewed the idea of being knowledgeable about the disease and having an active role in decision making and treatments positively. They also viewed it as their responsibility if they wanted to feel equipped to engage with their medical providers and make decisions. Participant "sheltiemom" implied that ease of access to information via the internet did place some responsibility on the patient when she wrote "I don't think our doctors expect us to be educated but most probably appreciate it if we are. In this world where info is easier to access on the internet it is important for us all to be our own advocate and be informed."

Americans continue to go to their health providers for information first [13] and many view their use of the internet to find information as supplemental to their primary care [16]. In this study, participants talked about conducting online research in preparation for a health care visit. This neutralizes claims that access to health information de-centralizes health care practice or, as Health 2.0 proponents suggest, revolutionizes it altogether. Rather, using the internet and social media to acquire, share, and create health knowledge expands the reach of information. It increases the participation of some patients and further normalizes resistance toward patriarchal medical practice as a whole, but is unlikely to unseat primary health care providers as central figures in care. 
The findings of this study demonstrate that blogging is a simultaneously empowering and disciplinary set of practices. The same mechanisms reproduce these practices, namely authoring public narratives about lived experience with illness and the consumption, generation, and dissemination of knowledge by patients. While blogging reproduces the discourse of self-responsibility and body governance, it also gives voice to experiences, which can empower the patient to challenge the dominant power structure upon which contemporary medicine is constructed and redirect narratives of illness and disability. Likewise, the practices of self-educating, producing experiential knowledge, reporting data, and disseminating knowledge can provide the patient with information that can be used to help treat their condition and which may give them a sense of greater agency.

In enacting these practices both by blogging and through blogging, these study participants create and shape a mediated space through which to practice participatory patient-hood. Critical concerns of how political, social, and cultural norms are scripted onto the body, suggest a passive patient, unaware or unconcerned with the forces working on her. Feminist theorists have sought to counter these assumptions by calling attention to how these forces are experienced [6,47]. Indeed, the participants in my study were very much aware of the interest in their bodies by a number of institutions: a health care system that simultaneously tries to treat, care for, regulate, profit from, and deny care to them; a state that reluctantly supports them with often too-meager resources; and a political and socio-cultural framework that constructs them as disabled and generates and reproduces a discourse of illness within which they negotiate their lives. This study has revealed that participatory patient-hood is contradictory: the burdens and expectations that are placed on them may be welcomed by patients for whom more information helps them manage the everyday realities of living with chronic illness and navigate the systems in which they have little choice but to participate.

\section{Conflicts of Interest}

The author declares no conflict of interest.

\section{References}

1. Bar-Lev, S. "We are here to give you emotional support": Performing emotions in an online HIV/AIDS support group. Qual. Health Res. 2008, 18, 509-521.

2. Han, J.Y.; Shaw, B.R.; Hawkins, R.P.; Pingree, S.; Mctavish, F.; Gustafson, D.H. Expressing positive emotions within online support groups by women with breast cancer. J. Health Psychol. 2008, 13, 1002-1007.

3. Høybye, M.T.; Johansen, C.; Tjørnhøj-Thomsen, T. Online interaction. Effects of storytelling in an Internet breast cancer support group. Psychooncology 2005, 14, 211-220.

4. Keim-Malpass, J.; Steeves, R.H. Talking with death at a diner: Young women's online narratives of cancer. Oncol. Nurs. Forum 2012, 39, 373-378.

5. Orgad, S. The transformative potential of online communication: The case of breast cancer patients' Internet spaces. Fem. Media Stud. 2005, 5, 141-161.

6. Pitts, V. Illness and Internet empowerment: Writing and reading breast cancer in cyberspace. Health Interdiscip. J. Soc. Stud. Health Illn. Med. 2004, 8, 33-59. 
7. Sandaunet, A.-G. A space for suffering? Communicating breast cancer in an online self-help context. Qual. Health Res. 2008, 18, 1631-1641.

8. Barak, A.; Boniel-Nissim, M.; Suler, J. Fostering empowerment in online support groups. Comput. Hum. Behav. 2008, 24, 1867-1883.

9. Josefsson, U. Coping with illness online: The case of patients' online communities. Inf. Soc. 2005, 21, 133-153.

10. McBride, D. Cancer survivors find blogging improves quality of life. ONS Connect 2011, 26, 20.

11. Vilhauer, R.P. Perceived benefits of online support groups for women with metastatic breast cancer. Women Health 2009, 49, 381-404.

12. Miller, E.A.; Pole, A. Diagnosis blog: Checking up on health blogs in the blogosphere. Am. J. Public Health 2010, 100, 1514-1519.

13. Fox, S. The Social Life of Health Information; Pew Internet \& American Life Project: Washington, DC, USA, 2011.

14. Wathen, C.N.; Harris, R.M. "I try to take care of it myself." How rural women search for health information. Qual. Health Res. 2007, 17, 639-651.

15. Harris, R.; Wathen, N.; Fear, J. Searching for health information in rural Canada. Where do residents look for health information and what do they do when they find it. Inf. Res. 2006, 12, Paper 274. Available online: http://www.informationr.net/ir/12-1/paper274.html (accessed on 11 June 2014).

16. Kivits, J. Everyday health and the Internet: A mediated health perspective on health information seeking. Sociol. Health Illn. 2009, 31, 673-687.

17. Crooks, V.A. "I go on the Internet; I always, you know, check to see what's new": Chronically ill women's use of online health information to shape and inform doctor-patient interactions in the space of care provision. ACME Int. E-J Crit. Geogr. 2006, 5, 50-69.

18. Barker, K.K. Electronic support groups, patient-consumers, and medicalization: The case of contested illness. J. Health Soc. Behav. 2008, 49, 20-36.

19. Ziebland, S.; Wyke, S. Health and illness in a connected world: How might sharing experiences on the Internet affect people's health? Milbank Q. 2012, 90, 219-249.

20. Conrad, P.; Stults, C. The internet and the experience of illness. In Handbook of Medical Sociology; Bird, C.E., Conrad, P., Fremont, A.M., Eds.; Vanderbilt University Press: Nashville, TN, USA, 2010; pp. 179-191.

21. Fox, S. Mind the Gap: Peer to Peer Healthcare; Pew Internet and American Life Project: Washington, DC, USA, 2011. Available online: http://www.pewinternet.org/Reports/2011/20Mind-the-Gap/Part-1.aspx (accessed on 2 February 2012).

22. Sarasohn-Kahn, J. The Wisdom of Patients: Health Care Meets Online Social Media. Ihealth Reports. California HealthCare Foundation; April 2008. Available online: http://www.chcf.org/ topics/chronicdisease/index.cfm?itemID=133631 (accessed on 11 June 2014).

23. Mazanderani, F.; O’Neill, B.; Powell, J. "People power" or "pester power"? YouTube as a forum for the generation of evidence and patient advocacy. Patient Educ. Couns. 2013, 93, 420-425.

24. Henwood, F.; Wyatt, S.; Hart, A.; Smith, J. "Ignorance is bliss sometimes": Constraints on the emergence of the "informed patient" in the changing landscapes of health information. Sociol. Health Illn. 2003, 25, 589-607. 
25. Cline, R.J.W.; Haynes, K.M. Consumer health information seeking on the Internet: The state of the art. Health Educ. Res. 2001, 16, 671-692.

26. Demiris, G. The diffusion of virtual communities in health care: Concepts and challenges. Patient Educ. Couns. 2006, 62, 178-188.

27. Salmon, P.; Hall, G.M. Patient empowerment or the emperor's new clothes. J. R. Soc. Med. 2004, 97, 53-56.

28. Foucault, M. Power/Knowledge: Selected Interviews and Other Writings, 1972-1977; Gordon, C., Ed.; Pantheon Books: New York, NY, USA, 1980.

29. Rose, N. Inventing Our Selves: Psychology, Power, and Personhood; Cambridge University Press: Cambridge, UK, 1998.

30. Eytan, T. The Health 2.0 Definition: Not Just the Latest, the Greatest! Ted Eytan MD E-Health Patient Empower Divers. 2008. Available online: http://www.tedeytan.com/2008/06/13/1089 (accessed on 21 January 2013).

31. Levina, M. Our data, ourselves: Feminist narratives of empowerment in Health 2.0 discourse. In Cyberfeminism 2.0; Oh, Y.J., Gajjala, R., Eds.; Peter Lang Publishing: New York, NY, USA, 2012; First printing.

32. Rose, N.; Novas, C. Biological citizenship. In Global Assemblages: Technology, Politics and Ethics as Anthropological Problems; Ong, A., Collier, S., Eds.; Blackwell: London, UK, 2005; pp. 439-463.

33. Kopelson, K. Writing patients' wrongs: The rhetoric and reality of information age medicine. J. Adv. Compos. 2009, 29, 353-404.

34. Ziebland, S. The importance of being expert: The quest for cancer information on the Internet. Soc. Sci. Med. 2004, 59, 1783-1793.

35. Rothman, S.M.; Raveis, V.H.; Friedman, A.; Rothman, D.J. Health advocacy organizations and the pharmaceutical industry: An analysis of disclosure practices. Am. J. Public Health 2011, 101, 602-609.

36. Orgad, S. The cultural dimensions of online communication: A study of breast cancer patients' Internet spaces. New Media Soc. 2006, 8, 877.

37. Hutchinson, R. Dangerous liaisons? Ethical considerations in conducting online sociological research. In Proceedings of the TASA 2001 Conference: The Australian Sociological Association, The University of Sydney, Sydney, Australia, 13-15 December 2001. Available online: http://www.tasa.org.au/docs/conferences/2001_12/031201\%20Hutchinson.pdf (accessed on 11 June 2014).

38. Sudweeks, F.; Rafaeli, S. How do you get a hundred strangers to agree? Computer-mediated communication and collaboration. In Computer Networking and Scholarship in the 21 st Century; Harrison, T.M., Stephen, T.D., Eds.; University of New York SUNY Press: Albany, NY, USA, 1995.

39. Walther, J.B. Research ethics in Internet-enabled research: Human subjects issues and methodological myopia. Ethics Inf. Technol. 2002, 4, 205-216.

40. Elgesem, D. What is special about the ethical issues in online research? Ethics Inf. Technol. 2002, 4, 195-203.

41. King, S. Researching Internet communities: Proposed ethical guidelines for the reporting of results. Inf. Soc. 1996, 12, 119-127. 
42. Scharf, B. Beyond netiquette: The ethics of doing naturalistic discourse research on the Internet. In Doing Internet Research; Jones, S., Ed.; SAGE Publications: London, UK, 1999.

43. Waskul, D.; Douglas, M. Considering the electronic participant: Some polemical observations on the Ethics of on-line research. Inf. Soc. 1996, 12, 129-139.

44. Altheide, D. Ethnographic Content Analysis: Working Draft. Available online: http://www.public.asu.edu/ atdla/ecadraft.html (accessed on 2 June 2014).

45. Glaser, B.; Strauss, A. The Discovery of Grounded Theory: Strategies for Qualitative Research; Aldine Transaction: Piscataway, NJ, USA, 1967.

46. Charmaz, K. Constructing Grounded Theory: A Practical Guide through Qualitative Analysis, 1st ed.; Sage Publications: Thousand Oaks, CA, USA, 2006.

47. Ehrenreich, B.; English, D. For Her Own Good: 150 Years of the Experts' Advice to Women; Anchor Press: Garden City, NY, USA, 1978.

(C) 2014 by the author; licensee MDPI, Basel, Switzerland. This article is an open access article distributed under the terms and conditions of the Creative Commons Attribution license (http://creativecommons.org/licenses/by/3.0/). 